\title{
Human papilloma virus genotypes associated with cervical cancer in Senegal
}

\author{
Niane Khadidiatou ${ }^{1,2,3 *}$, Diagne Cheikh Tidiane ${ }^{4}$, Diop Gora ${ }^{1,2,3}$, Dia Ndongo $^{4}$, Talla Cheikh ${ }^{5}$, Loucoubar Cheikh ${ }^{5}$, Ndiaye Moussa ${ }^{1,2,3}$, Niang \\ Mbayame $^{4}$, Diallo Aissatou ${ }^{4}$, Sembene Pape Mbacke ${ }^{1}$, KA Sidy ${ }^{6,7}$, Dieye Alioune ${ }^{8}$, Sall Amadou Alpha and Dem Ahmadou ${ }^{6,7}$ \\ ${ }^{1}$ Department of Animal Biology, Faculty of Science and Technology, Postulant Unit of Genetic, Genomic and Bioinformatic of Infectious Diseases, Cheikh Anta \\ DIOP University, Senegal \\ ${ }^{2}$ ImmunoGenetic Unit, Institute Pasteur Dakar, Senegal \\ ${ }^{3}$ Immunology \& Biology of Infectious Diseases Unit, Institute Pasteur Dakar, Senegal \\ ${ }^{4}$ Virology Unit, Institute Pasteur Dakar, Senegal \\ ${ }^{5}$ Epidemiology and Biostatistics of Infectious Diseases Unit, Institute Pasteur Dakar, Senegal \\ ${ }^{6}$ Department of Cancer, Faculty of Medicine and Ondontology, Cheikh Anta DIOP University, Senegal \\ ${ }^{7}$ Department of Oncology, Institute-Juliot-Curie, Hospital Aristide LeDantec, Senegal \\ ${ }^{8}$ Department of Immunology, Faculty of Medicine, Pharmacy and Ondontology, Cheikh Anta DIOP University, Senegal \\ ${ }^{9}$ Director, Institute Pasteur Dakar, Senegal
}

\begin{abstract}
Background: Cases of cervical cancer are increasing steadily in sub-Saharan Africa, with over 75,000 new cases and nearly 50,000 deaths a year. In Senegal, pathologies such as cervical cancer are one of the top causes of death and the Human papillomavirus (HPV) is its etiological agent.

Methods: The study group was made up of Senegalese women with cervical cancer who came for consultation or hospitalized at the Juliot Curie Center in Le Dantec. Total DNA from the 120 cervical biopsies was extracted using the Qiagen method (Qiagen Tissue Kit). Three methods were used to detect HPV genotypes: SANGER sequencing genotyping (Applied Biosystems), the real-time PCR approach technique (HPV 16 \& 18 Real Time PCR kit) and the Chippron genotyping approach (kit HPV) 3.5 LCDArray).

Results: In this study, all cervical samples taken from women with histologically confirmed cervical cancer had at least one HPV genotype detected. The most common types of HPV detected in women with one or more HPV infections were HPV 16 (consistently detected in all of our 59 patients), 18 (83\%), 45 (33\%), 33 (31\%), $59(28 \%), 35(12 \%), 31(11 \%), 58(8 \%), 39$ and $73(4 \%), 44,54$ and $68(3 \%)$ and the rest less than $1 \%$. It was also noted that most women were infected with two or more high-risk HPVs $(75,83 \%)$, and that the latter were particularly prevalent in patients aged 45 to 55 years.
\end{abstract}

Conclusion: In view of the results obtained in the present study, the use of the new Gardasil- $9{ }^{\circledR}$ vaccine which operates against 9 HPV genotypes $(6,11,16,18,31$, $33,45,52$ and 58) could provide results effective prevention of cervical cancer in adolescent girls or young Senegalese.

\section{Background}

Cervical cancer is the fourth commonest cancer affecting female population in the world, and the seventh most common cancer in the general population worldwide [1]. The disease is also the fourth leading cause of cancer death among women with 311,000 associated deaths in 2018. The highest regional incidence and mortality rates are seen in Africa, especially in Eastern (Malawi, with the highest mortality rate; and Zimbabwe) and Western Africa (Guinea, Burkina Faso, and Mali). Globally, it was previously admitted that low- and middle-income countries account for almost $90 \%$ of the burden of cervical cancer [2] due to insufficient awareness, lack of effective screening programs, and late clinical presentation. In addition, reports of trends in cervical cancer mortality in these countries have been limited by poor data quality and inaccurate estimates of population [3]. Additionally, in most of these countries, especially in sub-Saharan Africa, there is no cancer registry. Human papillomavirus (HPV) is a causative agent of cervical cancer that has been detected in $99.7 \%$ of cervical squamous cell carcinoma and in $94-100 \%$ of cervical adenocarcinoma [4]. HPV is transmitted through sexual intercourse or skin-to-skin genital contact [5], and persistent infection with high-risk HPV (HR-HPV) is the major cause of cervical intraepithelial neoplasia and invasive cervical cancer [6-8]. In general, most infections resolve on their own, as the immune response controls infection and prevents progression to precancerous lesions [9]. Papillomaviruses are circular, nonenveloped double-stranded DNA viruses with a genome length of $8 \mathrm{~kb}$. More than $200 \mathrm{HPV}$ genotypes have been reported and grouped into cutaneous and mucosal types according to their site of infection, and then subdivided into high risk (HR) and low risk (LR) types, depending on their association with a particular infection. Malignant disease (IARC,

${ }^{*}$ Correspondence to: Khadidiatou Niane, Department of Animal Biology, Faculty of Science and Technology, Postulant Unit of Genetic, Genomic and Bioinformatic of Infectious Diseases, Cheikh Anta DIOP University, Senegal, Tel: +22-1777509207; E-mail: dija.bec@gmail.com

Key words: Mamnarenavirus, HTLV, Hepatitis E, seroprevalence, Colombia

Received: October 10, 2021; Accepted: November 17, 2021; Published: November 24, 2021 
2011). Based on epidemiological studies conducted mainly in developed countries, HPV16 and HPV18 are the two most common types of HR in cervical cancer, accounting for about $70 \%$ of all cases worldwide [10]. Sensitivity to risk factors for cervical cancer may facilitate public participation in screening campaigns, including young age at first intercourse [11,12], multiple sexual partners [13], multiparity [14,15], human papillomavirus infections $[8,16]$, the first term pregnancy [17]. Similarly, early research for help may be encouraged if women in middle-income countries are more aware of the symptoms of cervical cancer - menopausal vaginal bleeding, postcoital vaginal bleeding, superficial vaginal discharge, and lower abdominal pain $[18,19]$.

In Senegal, a West African country, a high-incidence and cervical cancer mortality area [1], data on cervical cancer and related genotypes are scarce. While genotype HPV-16 is the most common cervical cancer genotype in the world, the prevalence of other genotypes varies geographically. These data are highly variable and incomplete in Africa. Thus, the prevalence and distribution of HPV genotypes in Africa among women with invasive cervical cancer is necessary. Until now, two vaccines were available: the " old " Gardasil ${ }^{\circ}$, which contains two oncogenic HPV genotypes (HPV 16 and 18) and two other genotypes of HPV responsible for condyloma acuminata, and Cervarix ${ }^{\oplus}$, which contains HPV 16 and 18 . Both vaccines provide $70 \%$ protection against cervical cancer. To cover a broader spectrum of oncogenic HPV, a new Gardasil- $9^{\circ}$ vaccine was developed in 2016 with additional genotypes included (HPV 31, 33, 45, 52 and 58) and an expected protection against $90 \%$ of HPV-induced cervical cancers.

In Senegal, a study of a general population of women aged 18 and over in many regions [20] showed that the risk of HPV infection was estimated at $22.8 \%$. Mbaye et al. [20] also demonstrated that the HPV 31.52 and 53 genotypes were the most prevalent in the general population of women in Senegal. Here, we have set ourselves the goal of studying the distribution of HPV genotypes in Senegalese women with confirmed cervical cancer in order to see the decrease in the percentage of these cases of cervical cancer with introduction of the Gardasil vaccine- $9^{\circ}$.

\section{Methods}

\section{Study population}

This study was funded by the Institut Pasteur in Dakar. This was a cross-sectional study on cervical cancer surveillance conducted between 2013 and 2017. HPV genotype screening was performed on 120 samples of cancerous tissue. These tissues were biopsies made at the Joliot Curie Institute of the Aristide Le Dantec Hospital in Dakar on women with cervical cancer. These patients came from different parts of Senegal and hadj a pathology of the Cervine. All mentally and physically competent women aged 18 or older diagnosed with invasive cervical cancer (ICC) are included in the study after receiving the necessary counseling and consent to participate in the study. All patients with HIV infection were excluded. Patients were free to refuse inclusion (although all the patients we met agreed to participate in the study). For each consenting woman, data relating to age, sex, place of birth, place of residence, year of tumor diagnosis, tumor site, histology, clinic, received and the evolution of the disease, are collected on a dedicated form.

\section{DNA extraction, HPV L1 gene and PCR-Sanger Sequencing}

For each sample DNA was extracted from tissue using the Qiagen DNeasy ${ }^{\oplus}$ BloodaTissue Kit (QIAGEN, Valencia, CA, USA) according to the manufacturer's recommendations. A $450 \mathrm{bp}$ long fragment of the HPV L1 gene was targeted using the MY09/MY11 consensus primers previously described [21]. The PCR reactions were performed using a
Gotaq ${ }^{\circ}$ Green Master Mix (Promega, Germany) in a total volume of $25 \mu \mathrm{l}$ containing $5 \mu \mathrm{l}$ of genomic DNA $(5 \mathrm{ng} / \mu \mathrm{l}), 1.5 \mu \mathrm{l}$ of each primer

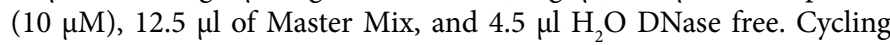
conditions were as follow: initial denaturation step at $95^{\circ} \mathrm{C}$ for $5 \mathrm{~min}$, 35 cycles including each $95^{\circ} \mathrm{C}$ for $30 \mathrm{~s}, 62^{\circ} \mathrm{C}$ for $45 \mathrm{~s}$, and $72^{\circ} \mathrm{C}$ for 1 min, and a final extension at $72^{\circ} \mathrm{C}$ for $10 \mathrm{~min}$. For positive samples, amplicons were purified using BioGel P100 gels (Bio-Rad) and nucleic acid quantified for Sanger sequencing. The corresponding genotypes were determined using Blast software and compared with the set of genomic sequences available in the GenBank database.

\section{HPV Genotyping Technique using the Chippron Approach (HPV 3.5 LCD-Array Kit)}

\section{(www.chipron.com)}

It consists of a specific identification of $32 \mathrm{HPV}$ genotypes, with a single hybridization on a combination of independent robust PCR amplifications in a matrix field. Combined PCR allows parallel and robust detection of HPV types at 5 target copies per reaction for HPV 16,18 , and 31 types and at 50 target copies for all others. Both, primer mixtures are directed against highly conserved motifs in the genome. Primer mixture 'A' generate fragments of about 450 bp in length; while mixture 'B' generates amplicons around 165 bp long (depends on the type of HPV). Generated PCR product of small amplicons were biotinylated, labeled and hybridized to species-specific capture probes immobilized on the surface of the LCD chip. A cascade of enzyme substrates allows short and highly stringent visualization of the bound amplicon, and each LCD chip contains eight identical microarrays separated into individually addressable small reaction chambers.

\section{Real-time PCR-genotyping using the Bionner approach}

The BIONEER team has designed a kit to detect HPV16 and HPV18 gentotypes by real-time PCR approach (rRT-PCR). Bionner tests are performed in a closed system in three steps: DNA extraction, RT-PCR steps and Data analysis.

\section{Statistical analysis}

Statistical analysis was performed to evaluate the global distribution and the association between Cervix Cancer clinical status and HPV genotypes via R software. HPV Genotypes estimate were obtain using a simulation algorithm via $\mathrm{R}$ logistic software ( $\mathrm{R}$ Development Core Team (2010)). Differences in HPV genotypes frequencies among stages of the disease (Figo classification groups), and other factors (age, marital status, gesture, parity, number of partners and profession), were examined using the chi-squared test, and differences were considered statistically significant for $\mathrm{p}$-values $<0.05$. Nominal $\mathrm{p}$ values were corrected under listed cofounders' factors such as age, marital status, gesture, parity, number of sexual partners and profession. For age, the women were classified into 3 age groups $(<45,45-55,>55)$ and 2 groups for the oncogene HPV genotypes ( $<$ or $=2$ and $>2$ ).

\section{Ethical approbation of the study}

Our protocol has been reviewed according to the rules issued by the National Committee for Ethics for Health Research (CNERS) of Senegal and in accordance with the procedures established by the University Cheikh Anta Diop Dakar (UCAD) for the ethical approval of any research involving human participants. Based on the information provided in the protocol, UCAD's Committee on Research Ethics (CER) considers that the research proposed, respects the appropriate ethical standards and, as a result, approves its execution under "Protocole 0224/2016/CER/UCAD". 
Table 1. Demographic and clinical characteristics (Age and Stade-classe figo)

\begin{tabular}{|l|c|c|c|c|c|c|}
\hline & \multicolumn{3}{|c|}{ Age } & \multicolumn{3}{c|}{ Figo class stade } \\
\hline & $<45$ & $45-55$ & $>55$ & Stade II & Stade III & Stade IV \\
\hline $\begin{array}{l}\text { Number of } \\
\text { patients }\end{array}$ & $\begin{array}{c}35 \\
(29.16 \%)\end{array}$ & $51(42.5 \%)$ & $\begin{array}{c}34 \\
(28.33 \%)\end{array}$ & $40(33.3 \%)$ & $53(44.2 \%)$ & $27(22.5 \%)$ \\
\hline
\end{tabular}

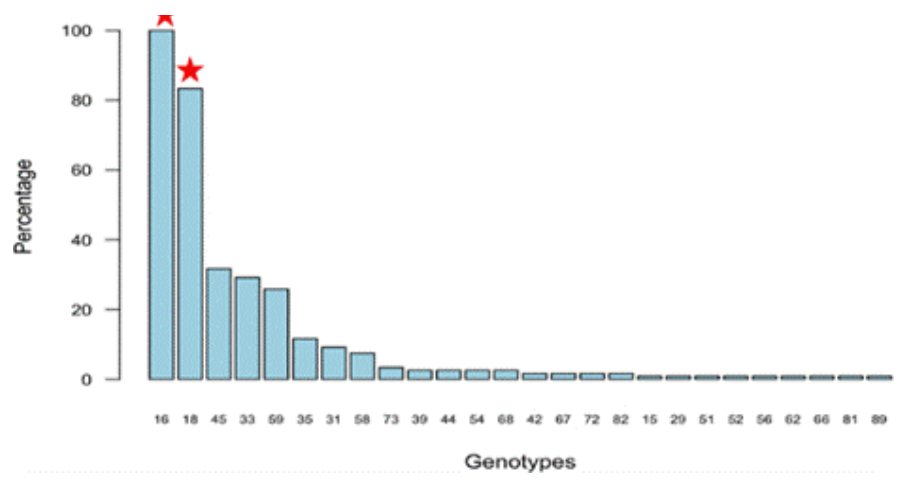

Figure 1: Distribution (prevalence) of genotypes in relation to the total number of patients. This analysis was done to see the prevalence of the different types of HPV detected in our study population. The most common genotypes in our population were HPV16 systematically detected in more than half of our patients, $18(83 \%), 45(33 \%), 33(31 \%)$, $59(28 \%), 35(12 \%)), 31(11 \%), 58(8 \%), 39$ and $73(4 \%), 44,54$ and $68(3 \%)$ and the rest less than $1 \%$

\section{Results}

\section{Demographic and clinical characteristics}

Between 2013 and 2017, 120 women from different regions of Senegal diagnosed with cervical cancer were included in the study (Tables 1 and 2). 62.5\% of these patients were part of the 2016-2017 series against $37.5 \%$ recruited between 2013 and 2015. New cervical biopsies were taken from each patient and screened for HPV. Regarding the age groups, 35 patients (29.2\%) were under 45 years old, 51 (42.5\%) between 45 and 55 years old and $34(28.33 \%)$ of the patients were over 55 years old. The age of the patients ranged from 27 to 85 years with a mean age at diagnosis of 50.62 years and a median age of 50 years. Regarding their clinical aspects, 40 of our patients, i.e., 33.3\%, were in stage II (figo class), 53 or $44.1 \%$ in stage III and 27 (22.5\%) in stage IV. Regarding the marital status, more than half of our patients $(65.83 \%)$ of our patients were under a polygamous regime against $34.17 \% .55 .83 \%$ of patients had their first sexual intercourse between 15 and 20 years old. The Dakar region had the most patients.

\section{HPV types of prevalence}

Several types of HPV were detected in this study. All our patients presented with HPV infection. Combining the results obtained with the three approach techniques, a total of $23 \mathrm{HPV}$ genotypes were detected in our patients (Figure 1). We found $24.16 \%$ (29 patients) of mono infections (single genotype infection) in our study population. The most common genotypes in our population were HPV16 systematically detected in more than half of our 223 patients, 18 (83\%), 45 (33\%), 33 (31\%), 59 (28\%), 35 (12\%)), 31 (11\%), 58 (8\%), 39 and 73 (4\%), 44, 54 and $68(3 \%)$ and the rest less than $1 \%$.

\section{HPV types of coinfections and cofactors}

Several co-functions were detected in our study. In fact, coinfections with two genotypes represented $33.33 \%$ (40/120) of cases (Figure 2). In 51 samples (42.5\%), more than two viruses were detected (Figure 2). Co-infections with $3 \mathrm{HPV}$ genotypes dominated (21.66\%) followed by 4 genotypes (12.5\%), 5 genotypes (5\%) and 6 genotypes $(1.66 \%)$. In both groups, coinfection with genotypes over 2 HRHPV (high risk HPV) dominated. We noted that co-infections with multiple HR-HPVs were predominant in polygamous patients $(p=0.02)$ compared to patients with monogamous status $(\mathrm{OR}=0.30)$ (Table 3 ). For the gesture criterion, co-infections with several genotypes (up to 6 genotypes) were more frequent in patients having had 6 or more pregnancies $(\mathrm{OR}=1.60)$. We also noted that co-infections with several genotypes were significantly associated with patients aged over 45 years $(\mathrm{OR}>1)$. Analysis of the association between HRHPV co-infections and age showed that HR-HPV co-infections were more frequent in "young" patients $(<45$ years) with 35 cases and those aged between 45 and 55 years old (41 cases). In both groups, co-infection with more than 2 HRHPV genotypes dominated (79 cases versus 41 with 2 or less).

\section{Discussion}

According to the World Health Organization, cervical cancer is the fourth most common cancer in the world and will kill more than 443,000 people worldwide by 2030 , of which nearly $90 \%$ in SubSaharan Africa. This high incidence may be justified by the lack of an adequate structure for diagnosis, screening and treatment. In Senegal, cervical cancer is the second most common cancer in women [22], and we have reported here a pilot study exclusively dedicated to the distribution of HPV genotypes among Senegalese women affected. Cervical cancer. Given that papillomaviruses cannot be cultivated in vitro, nor detectable by serological tests, molecular biology techniques represent a tool of choice for their detection and genotyping. Real-time PCRs were therefore chosen as the molecular approach but also the

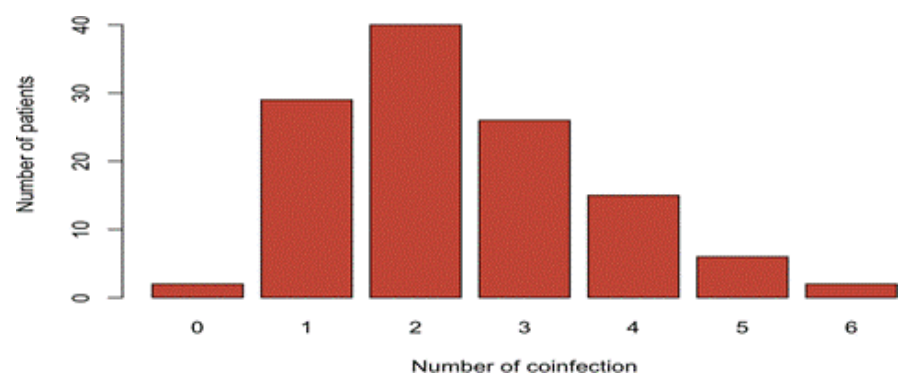

Figure 2: The distribution of coinfects according to the number of patients, Co-infections with 2 genotypes represented $33.33 \%$ (40/120) of cases. In 51 samples (42.5\%), more than two viruses were detected (Figure 27). Co-infections with 3 HPV genotypes dominated $(21.66 \%)$ followed by 4 genotypes $(12.5 \%), 5$ genotypes $(5 \%)$ and 6 genotypes $(1.66 \%)$.) followed by those with 3 types ( 26 patients), those with 4 types ( 15 patients), those with 5 types ( 6 patients) and those with 6 types ( 2 patients).

Table 2. Demographic and clinical characteristics (year of diagnosis, place of residence, Gestity and first sexual rapport)

\begin{tabular}{|c|c|c|c|c|c|c|c|c|c|c|c|c|}
\hline & \multicolumn{2}{|c|}{ Year of diagnosis } & \multicolumn{4}{|c|}{ Place of residence } & \multicolumn{3}{|c|}{ Gestity } & \multicolumn{3}{|c|}{ First sexual rapport } \\
\hline & 2013-2015 & 2016-2017 & West & Center & North & South & $<5$ & $5-10$ & $>10$ & $<15$ years & $\begin{array}{l}15 \text { years- } \\
20 \text { years }\end{array}$ & $>20$ years \\
\hline $\begin{array}{c}\text { Number of } \\
\text { patients }\end{array}$ & $48(40 \%)$ & $72(60 \%)$ & $58(48.33 \%)$ & $25(20.83 \%)$ & $11(9.16 \%)$ & $26(21.66 \%)$ & $\begin{array}{c}24 \\
(20 \%)\end{array}$ & $\begin{array}{c}84 \\
(70 \%)\end{array}$ & $\begin{array}{c}12 \\
(10 \%)\end{array}$ & $15(12.5 \%)$ & $67(55.83 \%)$ & $38(31.66)$ \\
\hline
\end{tabular}

West: Dakar, Thies, Diourbel; Center: Kaolack, Kaffrine, fatick. Louga ; North: Saint-Louis ; South: Kolda, Kédougou, Ziguicho 
Table 3. Correlation between risk factors and HR-HPV coinfects.

\begin{tabular}{|c|c|c|c|c|c|}
\hline & & $\leq 2$ HR-HPV & >2 HR-HPV & $p$-value & OR \\
\hline \multirow{2}{*}{ Sit } & Poly & $32(78.0)$ & $71(92.2)$ & \multirow{2}{*}{0.028} & - \\
\hline & Mono & $9(22.0)$ & $6(7.8)$ & & $\begin{array}{l}0.30(0.09-0.90 \\
\quad p=0.034)\end{array}$ \\
\hline \multirow{2}{*}{ Gest } & $\leq 6$ & $24(58.5)$ & $37(46.8)$ & \multirow{2}{*}{0.224} & - \\
\hline & $>6$ & $17(41.5)$ & $42(53.2)$ & & $\begin{array}{l}1.60(0.75-3.47, \\
\quad p=0.225)\end{array}$ \\
\hline \multirow{3}{*}{ Age } & $<45$ & $15(36.6)$ & 25 (31.6) & \multirow{3}{*}{0.778} & - \\
\hline & $>55$ & $12(29.3)$ & $22(27.8)$ & & $\begin{array}{c}1.10(0.42-2.88, \\
p=0.844)\end{array}$ \\
\hline & $45-55$ & $14(34.1)$ & $32(40.5)$ & & $\begin{array}{c}1.37(0.56-3.39, \\
\quad p=0.490)\end{array}$ \\
\hline \multirow[b]{2}{*}{ Stade } & II & $12(29.3)$ & $28(35.4)$ & \multirow[b]{2}{*}{0.496} & - \\
\hline & III \& IV & $29(70.7)$ & $51(64.6)$ & & $\begin{array}{l}0.75(0.33-1.68, \\
\quad p=0.497)\end{array}$ \\
\hline \multicolumn{6}{|c|}{$\begin{array}{l}\text { HPV: Human Papillomavirus; HR: High-Risk; Gest: Gestity; Pol: Polygamy; Gest: } \\
\text { Gestity; Mono: Monogamy; P: } p \text {-value; OR: Odds Ratio. }\end{array}$} \\
\hline
\end{tabular}

basic method, namely sequencing. This study has been submitted to the journal BMC infectious Disease and is awaiting an editorial decision.

All cervical samples taken from women with histologically confirmed cervical cancer had at least one HPV genotype detected. This result is justified because it is now accepted that certain human papillomaviruses are responsible for genital infections which can lead, after several tens of years, to cancer of the cervix. The most common types of HPV detected in women with one or more HPV infections were HPV 16 (consistently detected in all of our patients), $18(83 \%)$, $25845(33 \%), 33(31 \%), 59(28 \%), 35$ (12\%), 31 (11\%), 58 (8\%), 39 and $73(4 \%), 44,54$ and $68(3 \%)$ and the rest less than $1 \%$. The high prevalence of HPV16 and HPV18 reported in our study was expected, as these types are the two most common types of HPV worldwide [2326]. Several studies [27-29] have shown that genotypes 16 and 18 are responsible for $70.7 \%$ of cervical cancers, which explains why they were chosen as target for HPV vaccines. This percentage corresponds to the estimate of the worldwide distribution of the genotypes of human papillomaviruses responsible for invasive cancers [28]. This result agrees with that of Missaoui et al. [30], who found that HPV 16 is the most frequent virus among invasive squamous cell carcinomas $(47.6 \%, p=0.001)$ and adenocarcinomas $(80 \%, p<0.001)$ in North Africa (Tunisia). On the other hand, in Central Africa more precisely in Cameroon, the prevalence of the HPV 16 and HPV 18 genotypes represented $30.8 \%$ [31]. It also emerges that HPV 45 was very present in our study (33\%) which is in line with certain studies [32-35], which had shown that other genotypes (HPV45, 58, 52) had been reported as the second most common.

We also noted that most women were infected with at both high-risk HPV $(75,83 \%)$. This high co-detection rate is notably due to the high sensitivity of the Chippron real-time PCR test, which targeted a wide range of genotypes, but also to the fact that almost all of our patients were on a polygamous diet. Indeed, the association of co-functions and cervical cancer risk co-factors has shown that polygamy may involve the diversity of the genotypes noted as well as the high number of coinfections. Overall, it has been noted that the proportion of multiple $\mathrm{HPV}$ infections has increased in recent years from $4 \%$ to $15 \%$ [24], reflecting the use of newer tests more likely to detect multiple infections in recent studies. Multiple HPV infections could, in part, explain the peculiar aggressiveness and rapid progression of cervical cancer disease seen in Senegalese women, as it has been reported as an independent predictor of longer survival. low in another study [36]. However, the mechanism of the influence of multiple HPV infections on patient survival is not fully understood. We also noted that co-infections with more than 2 types of HR-HPV were particularly prevalent in patients aged 45-55, possibly due to viral persistence or latent HPV reactivation [37]. Our observations are comparable to those in the African study of histologically confirmed cancer cases, which found the average age of patients to be 48.5 years with a peak in the age group of 41-50 years, or $38.1 \%$ of detection of invasive cervical cancer, could currently be around 45-74 years. On the other hand, in countries where screening is organized, invasive cancer is discovered at an average age of 55 years. These figures correspond to the age of the patients at the time of diagnosis of the disease. Regarding marital status, multiple HR-HPV co-infections were significantly more frequent in polygamists. We also noted that women with more than six pregnancies were prone to multiple co-infections. Both results are consistent with previous results which clearly indicated that multiple pregnancies and high number of sexual partners increased the risk of HPV infection and persistence (IARC, 2016).

Based on the new Gardasil- $9^{\circ}$ vaccine which operates against 9 HPV genotypes $(6,11,16,18,31,33,45,52$ and 58$)$, only 5 cases of CHF were exclusively associated with non- vaccine types. Thus, in view of the results obtained in the present study, the use of this nonavalent vaccine could provide effective results in the prevention of cervical cancer in adolescent girls or young Senegalese, in the hope of preventing up to at $95 \%$ of CHF. However, additional studies including more patients are needed to better assess the real impact of this nonavalent vaccine.

Regarding the prospects for vaccination, the relatively high prevalence of the types presents in nonavalent vaccines (genotypes 16, $18,31,33,45$ and 58), Gardasil 9 shows that the latter could constitute a clear advance in the prevention of cervical cancer. infection of the uterus and papilloma virus (HPV) but also an additional means of screening in Senegal in order to reduce the risk of cervical cancer due to genotypes 16 and 18, which are among the known causes most frequent pre-cancerous lesions of the Matterhorn.

In sum, the overall frequency of HPV types detected in women with cervical cancer in Senegal was high for HPV16 and HPV18. Multiple infections were also very common. Determining the viral load of genotypes by quantitative methods would probably help to get an idea of the types or combinations of associated types that are more carcinogenic in Senegal.

\section{Conclusion}

This study showed that the overall frequency of HPV types detected in women with cervical cancer in Senegal was high for HPV16 and HPV18. Multiple infections were also very common. Indeed, the majority of our patients presented 2 or more HPV. In view of the results obtained in the present study, the use of the new Gardasil- $9^{\circ}$ vaccine which operates against 9 HPV genotypes $(6,11,16,18,31,33,45,52$ and 58) could provide results effective prevention of cervical cancer in adolescent girls or young Senegalese. Human papillomavirus vaccines were developed and marketed to help reduce the incidence of cervical cancer. They are based on the relationship between the development of cancer and the virus that causes precancerous lesions. We therefore do not yet have sufficient hindsight to assess their real effectiveness in reducing the incidence of cervical cancer. However, special attention should be paid to certain non-vaccine types (HPV 59 and 35 in particular) which could appear to be the main causes of cervical cancer in the context of HPV vaccination in Senegal. Polygamy could represent 
a cofactor in the occurrence of cervical cancer in Senegalese women. No association between high-risk HPV co-infections and cancerous stages. However, an increase in our cohort would be necessary to confirm these hypotheses.

\section{Ethics approval and consent to participate}

Consent was obtained from adults or legal representatives of participants. Our protocol was drafted according to the rules issued by the National Committee of Ethics for Health Research (CNERS) of Senegal and in accordance with the procedures established by the University Cheikh Anta Diop Dakar (UCAD) for the ethical approval of research persons. involving human participants. Based on the information provided in the protocol, UCAD's Research Ethics Committee (CER) considers that the proposed research meets appropriate ethical standards and, accordingly, approves its execution under "Protocol 0224 / 2016 / CER / UCAD".

\section{Availability of data and materials}

The datasets used and/or analysed during the current study available from the corresponding author on reasonable request.

\section{Funding}

This study was supported by grants from Senegal Ministry of Research and Institut Pasteur of Dakar. Indeed, the Institut Pasteur provided all the reagents but also covered the cost of the analyzes and the cost of the article.

\section{Authors contributions}

- NK, DCT, DN and DG concepted the study, the methodology, conducted the study, drafted the manuscript and approved the final version.

- TC and LC conducted the data analysis and approved the final version.

- $\mathrm{CD}$ and $\mathrm{KN}$ conducted the methodology, to performing molecular biology, and approved the final version.

- $\mathrm{KN}$ and DA2 contributed to the recruitment and managment of the Cervix Cancer Cases and approved the final version.

- DA2, DN and DA1 coordinated this study, revised the manuscript.

- All authors read and approved the final manuscript.

\section{Acknowledgements}

The authors are grateful to all the patients and medical staff who have generously collaborated in this study. Authors thanks to the staff of the Cancerology Aristide LeDantec Hospital (Dakar, Senegal) assistance in inclusion/recruitment. The Senegal Ministry of Education and Research and Institute Pasteur of Dakar (Senegal) supported the PhD Candidate NK.

\section{References}

1. Bray F, Ferlay J, Soerjomataram I, Siegel RL, Torre LA, et al. (2018) Global cancer statistics 2018: GLOBOCAN estimates of incidence and mortality worldwide for 36 cancers in 185 countries. CA Cancer J Clin 68: 394-424. [Crossref]

2. World Health Organization (WHO) (2014) World Cancer Report 2014. [Available from: http://publichealthwell.ie/node/725845].

3. Bailey HH, Chuang LT, duPont NC, Eng C, Foxhall LE, et al. (2016) American Society of Clinical Oncology Statement: Human Papillomavirus Vaccination for Cancer Prevention. J Clin Oncol 34: 1803-1812. [Crossref]
4. Steenbergen RD, de Wilde J, Wilting SM, Brink AA, Snijders PJ, et al. (2005) HPVmediated transformation of the anogenital tract. J Clin Virol 32: S25-S33. [Crossref]

5. Hernandez BY, Wilkens LR, Zhu X, Thompson P, McDuffie K, et al. (2008) Transmission of human papillomavirus in heterosexual couples. Emerg Infect Dis 14: 888-894. [Crossref]

6. Muñoz N, Bosch FX, de Sanjosé S, Tafur L, Izarzugaza I, et al. (1992) The causal link between human papillomavirus and invasive cervical cancer: a population-based casecontrol study in Colombia and Spain. Int J Cancer 52: 743-749. [Crossref]

7. Schiffman MH, Bauer HM, Hoover RN, Glass AG, Cadell DM, et al. (1993) Epidemiologic evidence showing that human papillomavirus infection causes most cervical intraepithelial neoplasia. J Natl Cancer Inst 85: 958-964. [Crossref]

8. Walboomers JM, Jacobs MV, Manos MM, Bosch FX, Kummer JA, et al. (1999) Human papillomavirus is a necessary cause of invasive cervical cancer worldwide. J Pathol 189: 12-9. [Crossref]

9. Rodríguez AC, Schiffman M, Herrero R, Wacholder S, Hildesheim A, et al. (2008) Rapid clearance of human papillomavirus and implications for clinical focus on persistent infections. J Natl Cancer Inst 100: 513-517. [Crossref]

10. Ramakrishnan S, Partricia S, Mathan G (2015) Overview of high-risk HPV's 16 and 18 infected cervical cancer: pathogenesis to prevention. Biomed Pharmacother 70: 103110. [Crossref]

11. Jimenez P, Thomas DB (1999) Has the use of pap smears reduced the risk of invasive cervical cancer in Guadalajara, Mexico? Int J Cancer 82: 804-809.

12. Louie KS, de Sanjose S, Diaz M, Castellsagué X, Herrero R, et al. (2009) Early age at first sexual intercourse and early pregnancy are risk factors for cervical cancer in developing countries. Br J Cancer 100: 1191-1197. [Crossref]

13. Brinton LA, Reeves WC, Brenes MM, Herrero R, Gaitan E, et al. (1989) The male factor in the etiology of cervical cancer among sexually monogamous women. Int $J$ Cancer 44: 199-203. [Crossref]

14. Castellsagué X, Muñoz N (2003) Chapter 3: Cofactors in human papillomavirus carcinogenesis--role of parity, oral contraceptives, and tobacco smoking. J Natl Cancer Inst Monogr 31: 20-28. [Crossref]

15. Brinton LA, Reeves WC, Brenes MM, Herrero R, de Britton RC, et al. (1989) Parity as a risk factor for cervical cancer. Am J Epidemiol 130: 486-496. [Crossref]

16. Bosch FX, de Sanjosé S (2007) The epidemiology of human papillomavirus infection and cervical cancer. Dis Markers 23: 213-227. [Crossref]

17. International Collaboration of Epidemiological Studies of Cervical Cancer (2006) Cervical carcinoma and reproductive factors: collaborative reanalysis of individual data on 16,563 women with cervical carcinoma and 33,542 women without cervical carcinoma from 25 epidemiological studies. Int J Cancer 119: 1108-1124. [Crossref]

18. Petignat P, Roy M (2007) Diagnosis and management of cervical cancer. BMJ 335: 765-768. [Crossref]

19. Lea JS, Lin KY (2012) Cervical cancer. Obstet Gynecol Clin North Am 39: 233-253. [Crossref]

20. Mbaye el HS, Gheit T, Dem A, McKay-Chopin S, Toure-Kane NC, et al. (2014) Human papillomavirus infection in women in four regions of Senegal. J Med Virol 86: 248-256. [Crossref]

21. Bauer HM, Ting Y, Greer CE, Chambers JC, Tashiro CJ, et al. (1991) Genital human papillomavirus infection in female university students as determined by a PCR-based method. JAMA 265: 472-477. [Crossref]

22. http://gco.iarc.fr/today/data/factsheets/populations/686-senegal-fact-sheets.pdf [Accessed 02 February 2019].

23. de Sanjose S, Quint WG, Alemany L, Geraets DT, Klaustermeier JE, et al. (2010) Retrospective International Survey and HPV Time Trends Study Group. Human papillomavirus genotype attribution in invasive cervical cancer: a retrospective crosssectional worldwide study. Lancet Oncol 11: 1048-1056. [Crossref]

24. Li N, Franceschi S, Howell-Jones R, Snijders PJ, Clifford GM (2011) Human papillomavirus type distribution in 30,848 invasive cervical cancers worldwide: Variation by geographical region, histological type and year of publication. Int $J$ Cancer 128: 927-935. [Crossref] 
25. Lagheden C, Eklund C, Lamin H, Kleppe SN, Lei J, et al. (2018) Nationwide comprehensive human papillomavirus (HPV) genotyping of invasive cervical cancer Br J Cancer 118: 1377-1381. [Crossref]

26. Liao L, Cheng H, Zeng F, Zhou W, Ding Y (2019) Prevalence and distribution of human papillomavirus genotypes among women with high-grade squamous intraepithelial lesion and invasive cervical cancer in Ganzhou, China. J Clin Lab Anal 33: e22708. [Crossref]

27. Ho GY, Bierman R, Beardsley L, Chang CJ, Burk RD (1998) Natural history of cervicovaginal papillomavirus infection in young women. $N$ Engl J Med 338: 423-428. [Crossref]

28. Muñoz N, Castellsagué X, Berrington de González A, Gissmann L (2006) Chapter 1: $\mathrm{HPV}$ in the etiology of human cancer. Vaccine 24: S3/1-10. [Crossref]

29. International Agency for Research on Cancer (IARC) (2005) Handbooks of cancer prevention Vol 10: cervix cancer screening.

30. Missaoui N, Hmissa S, Trabelsi A, Tahar Yacoubi M, Nouira A, et al. (2010) Prevalence of HPV infection in precancerous and cancerous lesions of the uterine cervix in Tunisia. Ann Biol Clin (Paris) 68: 297-303. [Crossref]

31. Marie TP, Appolinaire A, Charlotte NT, Claudine TT, Gisele1 KF, et al. (2018) Epidemiology of the infection in HPV in semi-urban Region of Cameroon: the experience of the District of Health of Baham, West-Cameroon. Health Sci Dis 19.
32. Mejía L, Muñoz D, Trueba G, Tinoco L, Zapata S (2016) Prevalence of human papillomavirus types in cervical cancerous and precancerous lesions of Ecuadorian women. J Med Virol 88: 144-152. [Crossref]

33. Wang J, Ploner A, Sparén P, Lepp T, Roth A, et al. (2019) Mode of HPV vaccination delivery and equity in vaccine uptake: A nationwide cohort study. Prev Med 120: 2633. [Crossref]

34. Schisler TM, Bhavsar AK, Whitcomb BP, Freeman JH, Washington MA, et al. (2018) Human papillomavirus genotypes in Pacific Islander cervical cancer patients. Gynecol Oncol Rep 24: 83-86. [Crossref]

35. Long W, Yang Z, Li X, Chen M, Liu J, et al. (2018) HPV-16, HPV-58, and HPV-33 are the most carcinogenic HPV genotypes in Southwestern China and their viral loads are associated with severity of premalignant lesions in the cervix. Virol J 15: 94. [Crossref]

36. Nogueira Dias Genta ML, Martins TR, Mendoza Lopez RV, Sadalla JC, de Carvalho JPM, et al. (2017) Multiple HPV genotype infection impact on invasive cervical cancer presentation and survival. PLoS One 12: e0182854. [Crossref]

37. Simon P, Poppe W (2008) Should the antipapillomavirus vaccination after the age of 25 be advised? J Gynecol Obstet Biol Reprod (Paris) 37: 748-752. [Crossref]

Copyright: (C2021 Khadidiatou N. This is an open-access article distributed under the terms of the Creative Commons Attribution License, which permits unrestricted use, distribution, and reproduction in any medium, provided the original author and source are credited. 